\title{
The Practical Exploration of Interactive Classroom in College English Teaching
}

\author{
Yao Yan \\ Weinan Normal University, Weinan, Shaanxi, 714000
}

Keywords: College English, Interactive, Classroom Teaching

\begin{abstract}
Under the guidance of the teacher, students as the main body of learning find, analyze, and solve problems, teachers and students create a pleasant, harmonious and efficient learning environment in the process. In the interactive classroom, the teachers change the traditional teaching concept from the former knowledge instructors to the learning guide, the organizers, the encouraging and the collaborators. Students also change their passive learning behaviors in the traditional classroom, and participate in learning activities more actively and actively. Teachers and students communicate with each other, inspire and complement each other, and achieve better teaching goals. This paper mainly takes college English classroom teaching as an example to explore the practical strategies of interactive classroom.
\end{abstract}

\section{The Important Role of Interactive English Teaching}

The important role of interactive classroom in English teaching is mainly reflected in the following aspects:

First of all, mobilize the students' enthusiasm for learning. Teaching activities are the activities of mutual participation of both teachers and students. In the traditional teaching process, teachers' "teaching" behavior is emphasized, but students' learning behavior is ignored. Students lack enthusiasm and initiative in learning process and can not guarantee good teaching effect. In interactive classroom, teachers interact with students, exert a subtle influence on students in their own teaching way, stimulate students' interest in learning, and achieve better teaching results. Secondly, cultivate the creative spirit of the students. In the traditional classroom teacher's lecture process, for all the students, learning can only be passively accepted [1-2]. Even if some of the students who are diligent in thinking are asking questions in the process of attending lectures, the teacher is too busy to take care of them, which will inhibit students' personality and creative spirit over time. The interactive teaching teacher is mainly responsible for the inspiration, questioning, guiding role, to encourage students to boldly questioning, independent thinking, and the courage to speak, and then were analyzed and evaluated by the teacher to the student's point of view, not only can enhance the self-confidence of students, teachers and students and discuss the process of mutual inspiration, form a good communication atmosphere, greatly to improve the efficiency of classroom teaching [3]. Finally, create a good interactive environment. Interactive teaching emphasizes the image, aesthetic and vivid in the classroom, create a good interactive space for students in the process of communication between teachers and students, guide students to play their own initiative, to create a harmonious atmosphere of the interaction, not only teachers can explore better teaching methods in the teaching process, give full play to their potential process and the students can also learn in two promote each other, work together to achieve the teaching goal.

\section{The Application of Interactive Teaching in College English Teaching}

In the course of College English teaching, there are various forms of interactive teaching, which are commonly used as follows:

\subsection{Oral presentation}

Oral presentations are usually placed in a formal class before ten minutes, reserved by the students oral presentations, display can be in the form of singing a song English songs, also can tell 
an English story, or short speech English display and so on, can be in the form of a student a few students at the same time, can also be show. After the students have completed the display, the teacher puts forward questions to other students for the contents of the students, or to analyze and evaluate the results of their display [4]. The main purpose of oral presentation is to improve students' oral ability and guide students to integrate into classroom teaching in a better state. Therefore, oral presentation time should not be too long, so teachers should control classroom rhythm reasonably.

\subsection{Panel discussion}

Group discussion is the best form of good interaction between students. The teacher designs the topic on the content of the teaching content by the students. For example, the related contents in the "Five Famous Symbols of American learning Culture", the teacher can let students in group discussions, students with 4-5 were divided into the discussion group, the design team task: to introduce the history background of American five cultural symbols and symbolic meaning in English, all members of the group to collect information and cooperation discuss the final design report, describes the related content of five American cultural symbols. In the course of the group discussion, the team members cooperate with each other to accomplish the task, not only to master knowledge and improve their ability, but also to cultivate the team spirit of the students.

\subsection{Problem teaching}

Effective learning methods will increase, decrease, ask, use and innovate, and the problem is the beginning of innovation. In the process of teaching, teachers should consciously lead students to think through questions, and cultivate their critical thinking and innovative thinking. In the interactive teaching process of College English, teachers design scientific and reasonable questions, students are invited to discuss culture, stimulate students' exploration spirit, promote their initiative to think, and experience the joy of learning. In practical teaching, the effectiveness of interaction between teachers and students is largely determined by the proper type of questioning [5-6]. In response to students' responses, classroom questions can be divided into cognitive and response types, in which cognitive types include display questions and reference questions. Display question is relatively low level cognition problem. The answer is unique. Referential question is a relatively high level of cognition. The answer is open-ended. It's a question raised by the questioner after deep excavation of the material. Responsive questions include basic fact questions, reasoning questions, social problems and so on. According to the difficulty and the induction degree of teachers, they can be divided into recall questions, inspirational questions, extended questions, etc. Teachers should choose different ways of questioning according to different teaching conditions. For example, in the introduction of new courses before the teacher to understand the students master the knowledge level of the old, can be used to recall questions; new lesson many enlightening questions, inducing students through "reviewing" and "new knowledge", link the old and new knowledge; the teaching process is the details of the question, question, inspiration the extension of questions and other methods used alternately, guide the students in the new field of knowledge exploration class is used step by step; referential question comprehensive and open, to stimulate students' learning motivation of knowledge thinking extends to the class, active thinking, learning by the students. Teachers should understand the role and significance of different types of questioning, strictly design according to teaching objectives, and adjust the way of questioning according to the actual situation of students and contents of textbooks, so as to improve the effectiveness of problem interaction [7].

\subsection{Other forms of interaction}

In addition to these common forms of interaction, role playing interaction, task interaction and debate competition are both applicable to the interactive form of College English class. The role play is mainly to choose the right teaching material content, play the role of students in the scene reproduction, and deepen the understanding and memory of knowledge in the role interaction. For example, "Busy Weekday Morning" in the learning content, the teacher can let people play table 
two daughter Sandy and mother Jane, according to their conversation aloud to rehearse, about 5 minutes after the two unscripted exercises. According to the content of the text, we should delete, add and reassemble the texts. Then we will play the role play, play the role of reducing the original text scene, and improve the vividness of role playing [8-9]. Role playing can fully activate the atmosphere of the classroom and stimulate students' interest in learning. However, the role playing of the teacher's ability to control the classroom rhythm is higher. The teacher should grasp the rhythm of the class reasonably in order to ensure the teaching efficiency. In addition, English debate competition can also be carried out in College English classes. For example, in the study of Legal related content and Moral Implication of Cloning ", the" clone "in the ethical and legal are controversial, the teacher can let the students debate on this topic, students are required to prepare in advance, collect information, prepare the debate. In the process of debate, try to speak English as much as possible. Of course, for some professional terms, if students have difficulties in understanding and remembering, they can be mixed in Chinese and English to express their views accurately. After the debate, all the students selected the best debating team, the best debating group, the best referee and so on.

\section{Matters of Attention in the Implementation of College English Interactive Teaching}

First, establish a harmonious relationship between teachers and students. To some extent, a harmonious teacher-student relationship is the basis of interactive teaching. Therefore, teachers should consciously create a diversified, symbiotic and harmonious relationship between teachers and students. The teacher to the students with appreciation and encouragement, especially some achievements are not outstanding students, the teacher should give them more respect and tolerance; others disagree with their own, there are serious shortcomings of students; teachers have to give them as much as possible to the recognition and appreciation, students must to pay, eliminate the psychological fear of the student, alleviate the psychological pressure of students, guide the students to actively participate in classroom activities, to express their views boldly, so as to improve their communicative ability [10]. In addition, the interaction between students is also very important, teachers can take teaching content into a classroom task, and the organization, management and supervision of the classroom activities, guide students to rational interaction, through the role of debate, play, occupation experience and a series of activities to students to become the masters of learning, more show personal space to play, for students. Secondly, we should guide students to interact with modern teaching technology. The application of modern teaching technology in classroom teaching is more and more widely, as a kind of auxiliary teaching means. The teacher will give full play to the role of modern information technology, optimize teaching resources, create a sound and pictures for the English classroom teaching environment, improve students' learning platform function, enrich the content, improve the convenience of students autonomous learning and retrieval of information. Finally, do a good job of knowledge interaction under the class. Any knowledge in life as the starting point, but also to people's daily life as the ultimate goal, the teacher should try to create the class and students the opportunity to interact with the students more social practice, such as the study of the tourist attractions of the commentary, translation of the hotel name, business English practice etc.. Let the students have more opportunities to contact the society, understand the society, expand the students' vision, so as to improve the students' English application ability.

\section{Conclusions}

Interactive teaching maximum respect for the main role of the students in the learning process, to establish a diversified, multi-level way of communication between teachers and students, arouse their learning enthusiasm and initiative of students, and to obtain feedback on students' learning effect, in order to improve the teaching methods better. However, any kind of teaching mode is determined rather than universal, and the construction of interactive classroom teaching is still in the preliminary stage, different types of classes, teaching content, teaching environment, combined 
with the actual situation to choose suitable teaching mode, teaching stage, and different teaching the goal, the teaching methods have different requirements. Therefore, in the actual teaching process, we should choose teaching methods flexibly and make full use of various forms of teaching methods, so as to improve the teaching effect and efficiency of College English.

\section{Acknowledgements}

This paper thanks from the support of fund projects: the key project of teaching reform in Shaanxi Provincial Education Department (project number: 17BZ045) and the teaching reform project at Weinan Teachers University level (project number: JG201731).

\section{References}

[1] Zhou X, Yang J. Reflection and Exploration of Interactive Teaching in College English Intensive Reading Classroom of Newly Built Universities under Network Environment in Minority Areas[C]// International Conference on Future Computer Science and Education. IEEE Computer Society, 2011:513-517.

[2] Sun J, Juanling W U. An Exploration of Interactively Asynchronous College English Teaching Mode in Network and Classroom [J]. Guide of Science \& Education, 2011, 129(4):887-894.

[3] Pan L, Guan J J. Game Between Innateness and Posteriority-Status Quo Analysis and Practical Exploration of College English Teaching in Sport Institutes [J]. Overseas English, 2015(15):230-232.

[4] Park K. Focus on Practice: Oliver Twist: an exploration of interactive storytelling and object use in communication [J]. British Journal of Special Education, 2015, 28(1):18-23.

[5] Liu Y, Cao J J, Zhang H W, et al. Exploration and Practice of the Two-way Interactive Teaching Mode in the NMR course [J]. Chinese Journal of Medical Physics, 2013, 30(6):4593-4596.

[6] Christel M G, Trybus J, Shah S D, et al. Bringing Biome Exploration into the Classroom Through Interactive Tablet Experiences[M]// Serious Games. Springer International Publishing, 2015:91-102.

[7] Gabbrielli R R P. Exploring Interactive Decision Making in the Classroom [J]. In English and American Literature, 2012:45-52.

[8] Kato S. Exploring Interactive Approach in Designing Reading Tasks in EFL Classrooms [J]. Journal of Fukui Prefectural University, 2004, 23:1-13.

[9] Zhou X, Yang J. Reflection and Exploration of Interactive Teaching in College English Intensive Reading Classroom of Newly Built Universities under Network Environment in Minority Areas[C]// International Conference on Future Computer Science and Education. IEEE Computer Society, 2011:513-517.

[10] Nijs L, Leman M. Interactive technologies in the instrumental music classroom: a case study with the Music Paint Machine[C]// Meryc. 2013:40-59. 